\title{
BMJ Open Physical activity and sedentary behaviour in current and former recreational and elite cricketers: a cross- sectional study
}

\author{
Nirmala K Panagodage-Perera, ${ }^{1,2,3,4}$ Garrett Scott Bullock (D) , ${ }^{2,5}$ Nigel K Arden, ${ }^{2}$ \\ Stephanie R Filbay (D) ${ }^{2,6}$
}

To cite: Panagodage-Perera NK, Bullock GS, Arden NK, et al. Physical activity and sedentary behaviour in current and former recreational and elite cricketers: a crosssectional study. BMJ Open 2021;11:e052014. doi:10.1136/ bmjopen-2021-052014

- Prepublication history and additional supplemental material for this paper are available online. To view these files, please visit the journal online (http://dx.doi.org/10.1136/ bmjopen-2021-052014).

Received 03 April 2021 Accepted 10 September 2021

Check for updates

(C) Author(s) (or their employer(s)) 2021. Re-use permitted under CC BY-NC. No commercial re-use. See rights and permissions. Published by BMJ.

For numbered affiliations see end of article.

Correspondence to Dr Garrett Scott Bullock; garrettbullock@gmail.com

\section{ABSTRACT}

Objective Former sports participants do not necessarily maintain high levels of physical activity (PA) across their lifespan. Considering physical inactivity in former athletes is associated with an increased susceptibility to inactivityrelated chronic diseases, research into PA behaviours in cricketers of all playing-standards is needed. The objective was to (1) describe PA and sedentary behaviour in current and former cricketers, and (2) determine the odds of current, former, recreational and elite cricketers meeting PA guidelines and health-enhancing PA (HEPA) compared with the general population.

Study design Cross-sectional survey.

Setting Questionnaire response, UK.

Participants 2267 current and former cricketers (age: $52 \pm 15$ years, male: $97 \%$, current: $59 \%$, recreational: $45 \%)$ participated. Cricketers were recruited through the Cricket Health and Wellbeing Study and met eligibility requirements (aged $\geq 18$ years; played $\geq 1$ year of cricket). Primary and secondary outcomes Age-matched and sex-matched data from Health Survey for England 2015 $(n=3201)$ was used as the general population-based sample. The International Physical Activity Questionnaire Short-Form assessed PA. Logistic regression, adjusted for age, sex, body mass index, alcohol consumption, smoking, education and ethnicity were used to meet the second aim.

Results $90 \%$ of current and $82 \%$ of former cricketers met UK PA guidelines. Current (OR 1.26, 95\% Cl 1.06 to 1.49)) and elite (OR 1.35, 95\% $\mathrm{Cl} 1.01$ to 1.78) cricketers had greater odds of meeting UK PA guidelines, and elite cricketers had greater odds of HEPA (OR 1.19, 95\% Cl 1.02 to 1.42), compared with the general population. Former cricketers had reduced odds (OR $0.78,95 \% \mathrm{Cl} 0.62$ to 0.99) of meeting the UK PA guidelines compared with the general population.

Conclusions Elite cricketers had a greater odds of meeting the PA guidelines and HEPA, compared with the general population. Former cricketers demonstrated reduced odds of meeting the PA guidelines compared with the general population. Strategies are needed to transition cricketers to an active lifestyle after retirement, since former cricketers demonstrated reduced odds of meeting the PA guidelines compared with the general population.
Strengths and limitations of this study

- Self-reported measures of physical activity (PA) are a widely used method to evaluate PA at the population level.

- The survey instrument was developed through patient and public involvement, and used validated questions from previous studies.

- Practical, self-report methods can lead to inaccuracies due to recall bias and response bias (eg, social desirability).

- Self-report data can overestimate or underestimate true PA, inactivity and sedentary behaviour.

- Female cricketers and ethnic minority groups were under-represented in our data.

\section{INTRODUCTION}

Inactivity is a major public health concern, and approximately 20 million adults (39\%) in the UK fail to meet physical activity (PA) recommendations. ${ }^{1}$ Physical inactivity is the fourth-leading risk factor for mortality (ranked ahead of obesity), contributing to one-in-six deaths from any cause worldwide. ${ }^{2}$ In addition, large amounts of sedentary time can have adverse health outcomes (even among people who meet recommended PA levels ${ }^{3}$ including all-cause mortality, type-2 diabetes, cancer and metabolic dysfunction). ${ }^{45}$ Sedentary behaviour displaces time spent in moderate-to-vigorous intensity $\mathrm{PA}$, compromising metabolic health. ${ }^{6}$ If the prevalence of inactivity was decreased by $10 \%-25 \%$, an estimated $533000-1.3$ million global deaths could be averted annually. ${ }^{2}$

Cricket is a bat-and-ball sport played in over 125 countries, ${ }^{7}$ by individuals of all ages and abilities. Playing formats are designated into several hours (twenty20 cricket), 1 day (one day internationals), and 5 consecutive days (test cricket) matches. Although the 2011 Compendium of Physical Activities 
categorised cricket as a source of moderate-intensity PA, ${ }^{8}$ the nature of cricket means that some players might be sitting for prolonged periods while their team is batting, or standing for prolonged periods in specific fielding positions. However, scientific data exploring the relationship between playing cricket, PA and sedentary behaviour among cricketers at all standards of play, particularly at recreational level, remain surprisingly sparse.

Additionally, only one qualitative study has investigated PA behaviour in former cricketers. ${ }^{9}$ This gap in research is significant because, contrary to popular assumptions, former sports participants do not necessarily maintain a high level of PA across their lifespan. ${ }^{10} 11$ Injuries, disabilities and older age have been identified as barriers for sport and PA participation and have led to sport retirement. ${ }^{12}$ Former cricketers are predisposed to joint pain, osteoarthritis and physical impairments compared with the general population, ${ }^{9}{ }^{13-16}$ which could negatively impact PA levels. ${ }^{17}$ Considering physical inactivity in former athletes is associated with an increased susceptibility to inactivity-related chronic diseases, ${ }^{18}$ research into PA behaviours in former cricketers of all playingstandards is needed.

Within current, former, recreational and elite cricketer subgroups, this study aimed to:

- Describe PA and sedentary behaviour.

- Determine the odds of meeting PA guidelines and health-enhancing PA (HEPA) compared with a general population sample.

\section{METHODS}

\section{Study design and recruitment}

This cross-sectional study was a part of the Cricket Health and Wellbeing Study, which was developed in collaboration with England and Wales Cricket Board; with input from current and former cricketers, as well as individuals with experience coaching cricket, sports medicine clinicians, and individuals with cricket-related research expertise. The Cricket Health and Wellbeing Study survey was an open survey containing 75 questions (10 per page, 8 pages total), which could not be randomised or alternated, and was administered online from 13 March 2017 to 14 May 2017 (online supplemental appendix 1 for questionnaire). Participants were informed of the principal investigator, their data would be protected through a deidentified encrypted database, and that their data would be stored at the University of Oxford. An incentive was detailed in which a signed cricket bat could be won by participant. An email invitation was received by 28152 individuals who were registered as current or former cricket players in England or Wales, from a variety of playing standards. Inclusion criteria were (1) aged $\geq 18$ years, (2) had played cricket for $\geq 1$ season and (3) no history of memory impairment. Participants had the ability to skip questions and return to answer later and save their work for later completion. Participants Research Electronic Data Capture (REDCap) software was used to formulate and deliver the questionnaire. Participant's IP address was used for unique identification with each participant assigned a unique identification number. No time frame was used for survey completion. The RedCap database was pilot-tested by three researchers for potential errors, branching logic and overall usability. ${ }^{19} 20$ The RedCap software allowed participants to save their answers to the survey questions and complete at a later date if desired.

\section{Patient and public involvement}

Prior to questionnaire design, qualitative interviews were performed with current and former cricketers from recreational and elite standards of play investigating PA and quality of life. These qualitative findings demonstrated a need for continued research into the relationship between cricket participation, PA, and health. Collaborating with cricket stakeholders, including coaches, current and former cricketers, and medical professionals that treat cricketers, the Cricket Health and Wellbeing questionnaire was developed and refined. Information has been disseminated to these key stakeholder groups through group meetings, and further disseminated through conferences, publications and invited presentations.

\section{Outcomes}

Physical activity

PA levels were assessed with the International Physical Activity Questionnaire Short-Form (IPAQ-SF) ${ }^{21}$ and interpreted with reference to the UK PA guidelines and classification criteria for HEPA. ${ }^{22}$ Meeting the UK PA guidelines was defined as performing at least $150 \mathrm{~min} /$ week of moderate-intensity PA, or $75 \mathrm{~min} /$ week of vigorous intensity PA, or an equivalent combination of these. ${ }^{22}$ HEPA was been defined as performing 1500 metabolic equivalent (MET)-minutes/week of total vigorous-intensity PA or 3000 MET-minute/week of total PA according to IPAQ criteria. ${ }^{21}$ Whereby one MET is defined as the energy cost of sitting quietly and is equivalent to a caloric consumption of $1 \mathrm{kcal} / \mathrm{kg} /$ hour.

\section{Sedentary behaviour}

No current guidelines exist for sedentary behaviour such as sitting time or how to break up duration of sedentary time throughout the day, owing to the complex relationship between the effects of sedentary time displacing time spent in moderate-to-vigorous PA. ${ }^{6}$ We categorised sedentary behaviour into $0-3,>3$ to 7 and $>7$ hours $/$ day. ${ }^{23}$

\section{Playing status and playing standard}

Participants were asked the following questions concerning playing status, 'What is your current cricket playing status?' Responses included: 'Currently playing cricket,' 'No longer playing cricket,' and 'Plan to return to cricket.' Participants were stratified into current and former cricketers (no longer playing cricket, or plan to return to cricket). Playing standard was assessed with the following question, 'What was the highest standard of cricket that you played for at least one season?' Responses included: international; county/premier league; academy or county age group; university; school; village or social; 
don't know. Participants were stratified into recreational (university, school, village or social) and elite (international or county/premier league, academy or county age group). 'Don't know' responses were excluded from analyses. ${ }^{1624}$

\section{Statistical analysis}

Prior to analyses, data were assessed for missing data (age $<1 \%$, gender $<1 \%$, ethnicity $<1 \%$, smoking status $<1 \%$, education $<1 \%$, comorbidities $1.1 \%$, IPAQ-SF $5.9 \%$, body mass index (BMI) 6.3\%, alcohol consumption $1.1 \%)$. Due to few missing data, a complete-case analysis was performed. Data were analysed using SPSS V.25.0 (IBM SPSS Statistics 2017), and descriptive statistics were used to describe participant characteristics and cricketing history. PA and sedentary behaviour in current, former, recreational and elite cricketers were analysed using descriptive statistics by age group.

To determine the odds of current, former, recreational and elite cricketers meeting UK PA guidelines and HEPA compared with a general population, binary logistic regression analyses were performed and crude and adjusted (adjusted for age, gender (male reference), alcohol consumption (units of alcohol over a typical week, categorised as 0 units (reference), 1-14 unit, $\geq 15$ units), smoking status (current vs former/never (reference)), highest level of education (university education (reference) vs non-university education), ethnicity (Caucasian (reference) vs Asian vs other) OR and 95\% CI were estimated. The decision on which variables to adjust for was based on previous qualitative work, ${ }^{9}$ clinical reasoning and current evidence. A full description of these variables is provided in online supplement. All underlying assumptions for logistic regression were evaluated and met.

Health Survey for England (HSE) (an annual crosssectional survey of adults and children living in England) data $^{25}$ collected in 2015 was used as the representative population-based comparison cohort (study number: 8280). To be able to compare against a non-cricket playing population, from the original N=13 748 HSE cohort, data from 148 individuals who were current or former cricketers were excluded from the comparison dataset. Additionally, data from individuals aged $<18$ years, those who did not self-complete the survey and people with missing data for demographic and PA variables were excluded (figure 1). The remaining sample was matched for gender ( $\%$ of individuals identifying as male and female) and age ( $\%$ of individuals in each age group: 18-29 years; $30-49$ years; $50-69$ years; $70-89$ years) to ensure that the general population sample were comparable in terms of age and gender with the sample of cricketers. ${ }^{26} \mathrm{~A}$ total of 3201 age-matched and sex-matched participants were included. Extracted data from the HSE included demographic characteristics (ie, ethnicity, BMI, level of education, smoking status and alcohol consumption), PA and sitting time, which were evaluated through the IPAQ-SF. The same methods were used to manage and categorise data from the HSE and Cricket Health and Wellbeing Study (CHWS), to enable comparison between cohorts.

\section{RESULTS \\ Participant characteristics}

The final analysis included data from 2267 current $(\mathrm{n}=1334,59 \%)$ and former $(\mathrm{n}=933,41 \%)$ cricketers and 3201 participants from a general population sample (figure 1 and table 1). On average, respondents started to play cricket aged $12 \pm 6$ (range 3-72) years, and played for $29 \pm 15$ (range 1 to 68 ) seasons, with $85 \%$ of respondents playing $>10$ games per season. The most common highest standard of play was at the village/social level
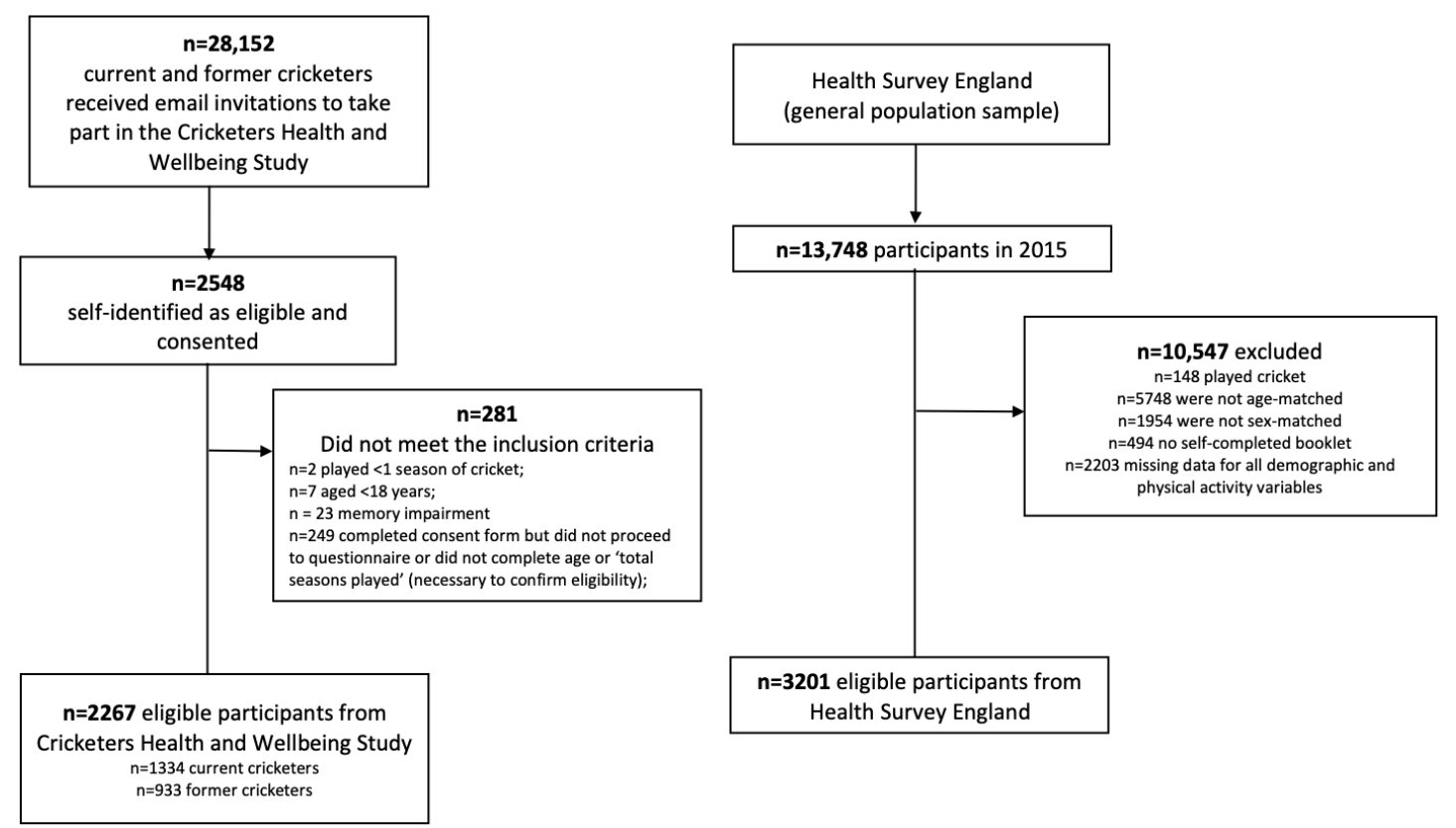

Figure 1 Participant flow from current and former cricketers and general population sample. 
Table 1 Characteristics of current $(n=1334)$ and former cricketers $(n=933)$ and a sample of the general population $(n=3201)$

\section{Current cricketers Former cricketers All cricketers General population}

$\mathrm{n}(\%)$

n (\%)

n (\%)

n (\%)

Participant characteristics

\begin{tabular}{|c|c|c|c|c|}
\hline $18-29$ years & $193(14.5)$ & $24(2.6)$ & $218(9.6)$ & $433(13.5)$ \\
\hline $30-49$ years & $566(42.5)$ & $163(17.5)$ & 730 (32.2) & $1127(35.2)$ \\
\hline $50-69$ years & $536(40.2)$ & $557(59.8)$ & $1095(48.3)$ & $1196(37.4)$ \\
\hline $70-89$ years & $38(2.9)$ & $188(20.2)$ & $226(10.0)$ & $445(13.9)$ \\
\hline \multicolumn{5}{|l|}{ Sex } \\
\hline Male & $1288(97.1)$ & $902(97.4)$ & 2194 (97.2) & $3090(96.5)$ \\
\hline Female & $39(2.9)$ & $24(2.6)$ & $63(2.8)$ & $101(3.5)$ \\
\hline \multicolumn{5}{|l|}{ Ethnicity } \\
\hline Caucasian & $1166(88.3)$ & 859 (93.2) & $2029(90.3)$ & $2849(89.1)$ \\
\hline Asian & $131(9.9)$ & $48(5.2)$ & $179(8.0)$ & $186(5.8)$ \\
\hline Other & $24(1.8)$ & $15(1.6)$ & $39(1.7)$ & $164(5.1)$ \\
\hline \multicolumn{5}{|l|}{$\operatorname{BMI}\left(\mathrm{kg} / \mathrm{m}^{2}\right)$} \\
\hline$<18.4$ & $6(0.5)$ & $0(0)$ & $7(0.3)$ & $37(1.3)$ \\
\hline $18.5-24.9$ & $387(31.0)$ & $208(23.8)$ & $595(27.9)$ & $791(27.2)$ \\
\hline $25-29.9$ & $599(47.9)$ & $413(47.2)$ & $1013(47.6)$ & $1213(41.7)$ \\
\hline $30-39.9$ & $239(19.1)$ & $228(26.1)$ & $469(22.0)$ & $788(27.1)$ \\
\hline$>40$ & $19(1.5)$ & $25(2.9)$ & $45(2.1)$ & $77(3.1)$ \\
\hline \multicolumn{5}{|l|}{ Highest level of education } \\
\hline $\begin{array}{l}\text { Higher education (university degree, } \\
\text { masters, PhD) }\end{array}$ & $655(49.5)$ & $373(40.4)$ & $1029(45.7)$ & 909 (34.9) \\
\hline Further education (certificate, diploma) & 267 (20.2) & $251(27.2)$ & $519(23.1)$ & $434(16.6)$ \\
\hline A level & $166(12.5)$ & $108(11.7)$ & 275 (12.2) & $511(19.6)$ \\
\hline GCSE/O level & $192(14.5)$ & $148(16.0)$ & $341(15.1)$ & $582(22.3)$ \\
\hline Other & $43(3.3)$ & $44(4.8)$ & $87(3.9)$ & $171(6.6)$ \\
\hline \multicolumn{5}{|l|}{ Smoking status } \\
\hline Never or ex-smoker & $1218(91.6)$ & $869(93.7)$ & $2091(92.5)$ & $2563(80.2)$ \\
\hline Current smoker & $112(8.4)$ & $58(6.3)$ & $170(7.5)$ & $632(19.8)$ \\
\hline \multicolumn{5}{|l|}{$\begin{array}{l}\text { Alcohol consumption over a typical week } \\
\text { (units) }\end{array}$} \\
\hline Does not consume alcohol & $196(14.9)$ & $154(16.6)$ & $350(15.6)$ & $691(21.8)$ \\
\hline Consumes 1-14 units of alcohol per week & $817(62.1)$ & $540(58.3)$ & $1357(60.5)$ & $1463(46.2)$ \\
\hline $\begin{array}{l}\text { Exceeds UK alcohol guidelines ( } \geq 15 \text { units } \\
\text { per week })^{44}\end{array}$ & $303(23.0)$ & $233(25.1)$ & $536(23.9)$ & $1013(32.0)$ \\
\hline
\end{tabular}

GCSE/O = General Certificate of Secondary Education or O-Level Education $\mathrm{BMI}$, body mass index.

(45\%) (table 2). PA was 'very important' for $65 \%(71 \%$ of current and $56 \%$ of former cricketers) of the respondents. One-in-three respondents $39 \%$ of current and $27 \%$ of former cricketers) were satisfied with their current activity level (table 3). The mean age that former cricketers played their last match was $48 \pm 12$ (range 14-82) years. Common reasons for ceasing cricket participation were time commitments (39\%), age (21\%), injury (16\%), no longer enjoying or good at playing cricket (12\%), personal reasons $(6 \%)$ and chronic pain $(6 \%)$.

\section{PA and sedentary behaviour}

Cricketers reported performing 2560 (722-4398) METS per week. The UK PA guidelines were met by $89.4 \%$ of elite cricketers, $86.2 \%$ of recreational cricketers and $83.0 \%$ of the general population sample (figure 2 ). The 
Table 2 Cricket and physical activity history in current and former cricketers

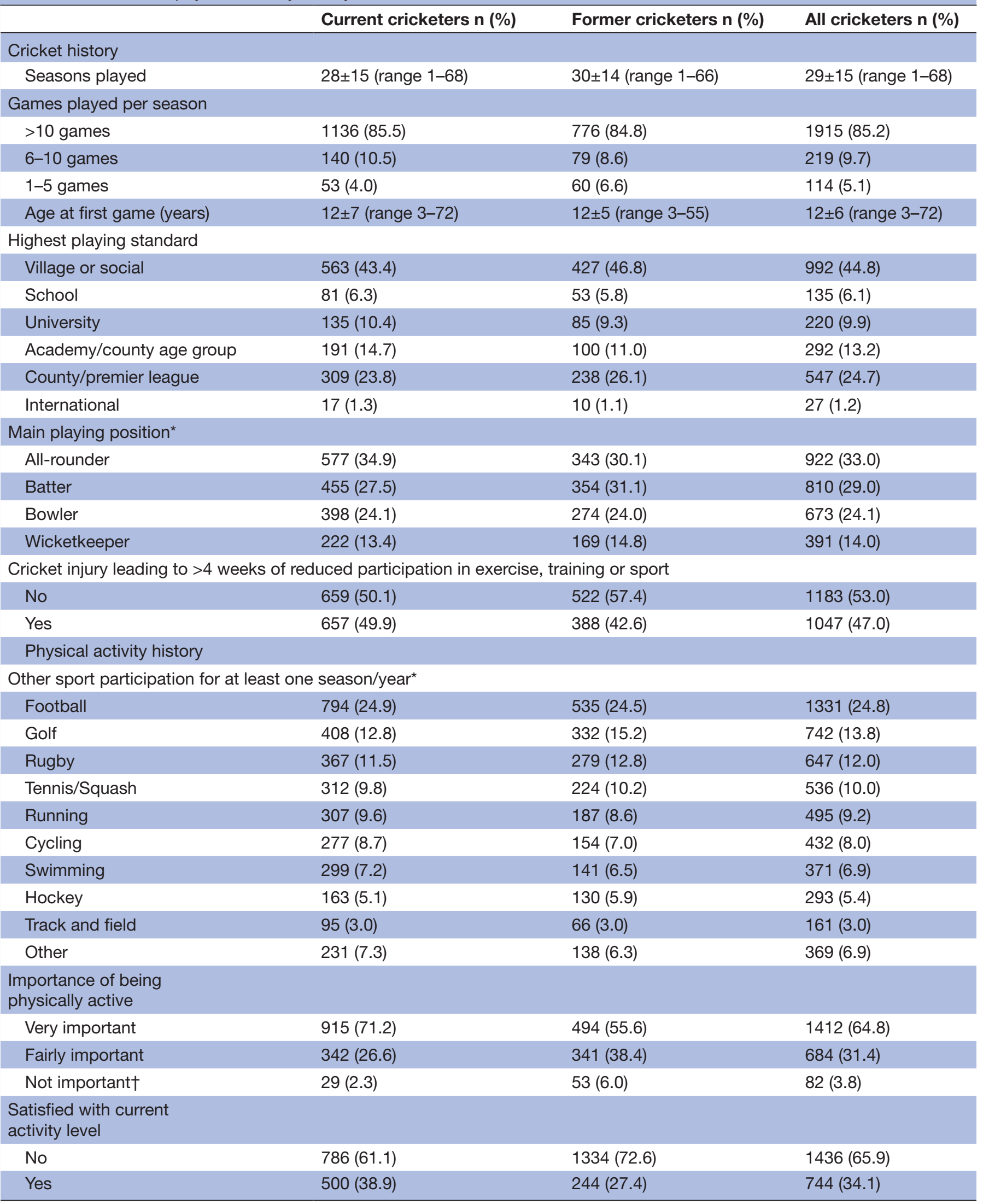

*Multiple responses were allowed, data are presented as a percentage of total responses.

†'Not that important' and 'not at all important' responses were combined. 
Table 3 Logistic regression analysis investigating odds of current, former, recreational and elite cricketers meeting PA guidelines and HEPA compared with a general population sample

\begin{tabular}{|c|c|c|c|}
\hline & & UK PA guidelines† & Health-enhancing PA \\
\hline \multicolumn{4}{|l|}{ Playing status } \\
\hline \multirow[t]{2}{*}{ Current cricketers $(n=1207)$} & Crude OR (95\% Cl) & $1.89(1.53 \text { to } 2.34)^{\star \star \star}$ & 1.15 (1.01 to 1.31$)$ \\
\hline & Adjusted* OR $(95 \% \mathrm{Cl})$ & $1.40(1.11 \text { to } 1.77)^{\star \star}$ & 1.08 (0.93 to 1.25$)$ \\
\hline \multirow[t]{2}{*}{ Former cricketers $(n=871)$} & Crude OR $(95 \% \mathrm{Cl})$ & 0.97 (0.79 to 1.19$)$ & $0.84(0.72 \text { to } 0.98)^{\star}$ \\
\hline & Adjusted* OR $(95 \% \mathrm{Cl})$ & $0.78(0.62 \text { to } 0.99)^{\star}$ & 0.89 (0.75 to 1.05$)$ \\
\hline General population $(n=3201)$ & & Reference group & \\
\hline \multicolumn{4}{|l|}{ Playing standard } \\
\hline \multirow[t]{2}{*}{ Elite cricketers $(n=780)$} & Crude OR $(95 \% \mathrm{Cl})$ & $1.72(1.35 \text { to } 2.20)^{\star \star \star}$ & $1.27(1.08 \text { to } 1.49)^{\star \star}$ \\
\hline & Adjusted* OR (95\% Cl) & $1.40(1.07 \text { to } 1.83)^{*}$ & $1.26(1.06 \text { to } 1.49)^{\star \star}$ \\
\hline \multirow[t]{2}{*}{ Recreational cricketers $(n=1214)$} & Crude OR $(95 \% \mathrm{Cl})$ & $1.28(1.05 \text { to } 1.54)^{*}$ & 0.89 (0.79 to 1.02$)$ \\
\hline & Adjusted* OR $(95 \% \mathrm{Cl})$ & 0.97 (0.77 to 1.18$)$ & 0.87 (0.75 to 1.01$)$ \\
\hline General population $(n=3201)$ & & Reference group & \\
\hline
\end{tabular}

Recreational cricketers=highest level of play: village/social or school/university.

Elite cricketers=highest level of play: international, county/premier league, academy or county age group.

${ }^{*} \mathrm{P} \leq 0.05 ;{ }^{* *} \mathrm{p} \leq 0.01 ;{ }^{* *} \mathrm{p}<0.001$.

†Adjusted for age, sex, alcohol consumption, smoking status, level of education and ethnicity.

¥The reference category is not meeting UK PA guidelines

$\S$ The reference category is not meeting health-enhancing PA.

HEPA, health-enhancing PA; PA, physical activity.

most inactive subgroup of cricketers were former cricketers aged $30-49$ years, whereby $26 \%$ did not meet the PA guidelines and $32 \%$ were achieving HEPA (figure 2). Current, former, recreational and elite cricketers were less sedentary, compared with the age-matched general population sample (figure 3).

\section{The odds of current, former, recreational and elite cricketers meeting PA guidelines and HEPA compared with a general population sample}

After adjusting for covariates, current cricketers had a 1.3 (95\% CI 1.0 to 1.7$)$ greater odds of meeting UK PA guidelines, and former cricketers had a 0.78 (95\% CI 0.62 to 0.99 ) reduced odds of meeting the UK PA guidelines, compared with the general population sample. The crude analysis showed an increased odds of HEPA for current cricketers (1.15 (95\% CI 1.01 to 1.31 ) ) and a reduced odds of HEPA for former cricketers $(0.84$ (95\% CI 0.72 to 0.98$)$ ), compared with the general population sample, although these relationships did not remain after adjusting for covariates (table 3 ).

After adjusting for covariates, elite cricketers had a greater odds of meeting the UK PA guidelines (1.35 (95\% CI 1.01 to 1.78$)$ ) and HEPA (1.19 (95\% CI 1.02 to 1.42)) compared with the general population sample. The crude analysis found a greater odds of meeting the UK PA guidelines (1.28 (95\% CI 1.05 to 1.54$)$ ) in recreational cricketers compared with the general population, however, this relationship did not remain after adjusting for covariates (table 3 ).

\section{DISCUSSION}

Our results suggest that cricket participation at a high standard is likely to provide a sufficient source of PA, although the PA benefits of cricket are less apparent at a recreational level. Of concern was that former cricketers had a reduced odds of meeting UK PA guidelines compared with an age and sex matched general population sample.

\section{Cricket as a lifelong PA}

There is a substantial body of evidence highlighting that increased levels of PA can bring a wide range of health benefits for individuals and communities. ${ }^{27-31}$ Often, PA participation is not only a planned behaviour with intention; it can become a routine incorporated into everyday life, performed with a degree of automaticity (ie, habit). ${ }^{32}$ PA habits established in childhood are carried into adulthood through adolescence. ${ }^{33}$ As expected, compared with an age-matched and sex-matched general population, current and elite cricketers reported higher PA levels. However, recreational cricketers did not demonstrate differences in PA levels compared with the general population. These discrepancies may be due to the contrasting training and competition requirements of elite and recreational cricketers. ${ }^{34}$ Based on these findings, healthcare providers should be aware that participation in recreational cricket does not necessarily result in meeting the PA guidelines. Some recreational cricketers may benefit from strategies to increase PA levels.

It should be noted that although cricket may provide a sufficient source of PA, our results suggest former 


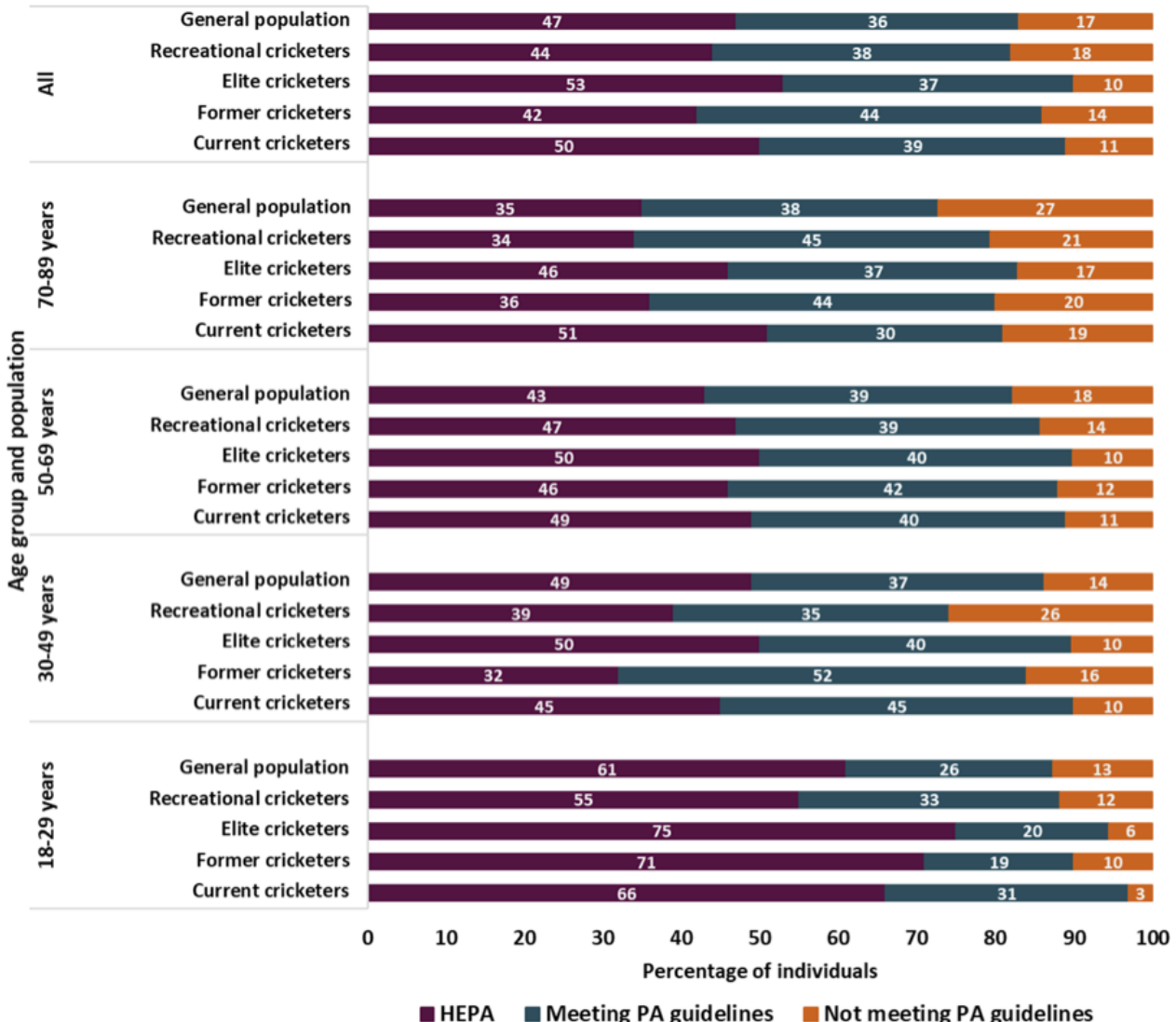

Figure 2 Physical activity (PA) levels in current and former elite and recreational cricketers, and a general population-based sample meeting PA guidelines=150 min/week of moderate-intensity PA, 75 min/week of vigorous-intensity PA or an equivalent combination of these. Defined as performing $1500 \mathrm{MET}-\mathrm{min} /$ week of total vigorous-intensity PA or $3000 \mathrm{MET}-\mathrm{min} /$ week of total PA according to IPAQ criteria. Recreational cricketers=highest level of play: village/social or school/university high-performance cricketers=highest level of play at an elite level: international, county/premier league, academy or county age group. HEPA, health-enhancing PA; MET, metabolic equivalent.

cricketers may not maintain PA levels after ceasing to play the sport. A busy lifestyle and time constraints have been identified as barriers to maintaining a physically active lifestyle in former professional cricketers. ${ }^{9}$ Our findings corroborate with this research, since more than one in three former cricketers cited time constraints as the main reason for cricket retirement. The average age for ceasing cricket participation was 48 years, potentially owing to the time pressures individuals' face in their multiple roles during this stage of life. Therefore, to sustain lifelong $\mathrm{PA}$, it is crucial to make sporting activities more accessible and time efficient. Cricket matches have historically been played over entire days, but with the introduction of Twenty20 cricket, shorter formats of the game are now offered. Promoting the shorter format may allow for greater cricket participant retention.

\section{Inactivity and sedentary behaviour in former cricketers}

Understanding the factors affecting inactivity and sedentary behaviour is particularly important when many countries, including the $\mathrm{UK}$, are attempting to increase the population's activity levels. Public Health England and other organisations have a strong focus on getting as many people as active as possible for as long as possible. ${ }^{35}$ While attempts to address lifelong PA often focus on youth and adolescents, the needs of older adults and retired sport participants are rarely considered by sporting organisations and policy-makers. We found that both current and former cricketers, at high and low standards of play, were less sedentary than the general population. However, reported time spent sitting was still high, suggesting, further exploration into barriers to decrease sitting time. Strong evidence demonstrates the existence of a dose-response relationship between all-cause mortality and sedentary behaviour. ${ }^{42336}$ Spending large amounts of time being sedentary may increase the risk of some health outcomes, even among people who are active at the recommended levels. ${ }^{3}$ Sedentary behaviour is independently associated with all-cause mortality, type 2 diabetes, some types of cancer and metabolic dysfunction. $^{35}$ As a result, promoting sport participation as a PA intervention may potentially lead to decreased adult sedentary habits.

\section{Methodological considerations}

Self-reported measures of PA (eg, IPAQ) ${ }^{37}$ are a widely used method to evaluate PA at the population level. However, practical, self-report methods can lead to 


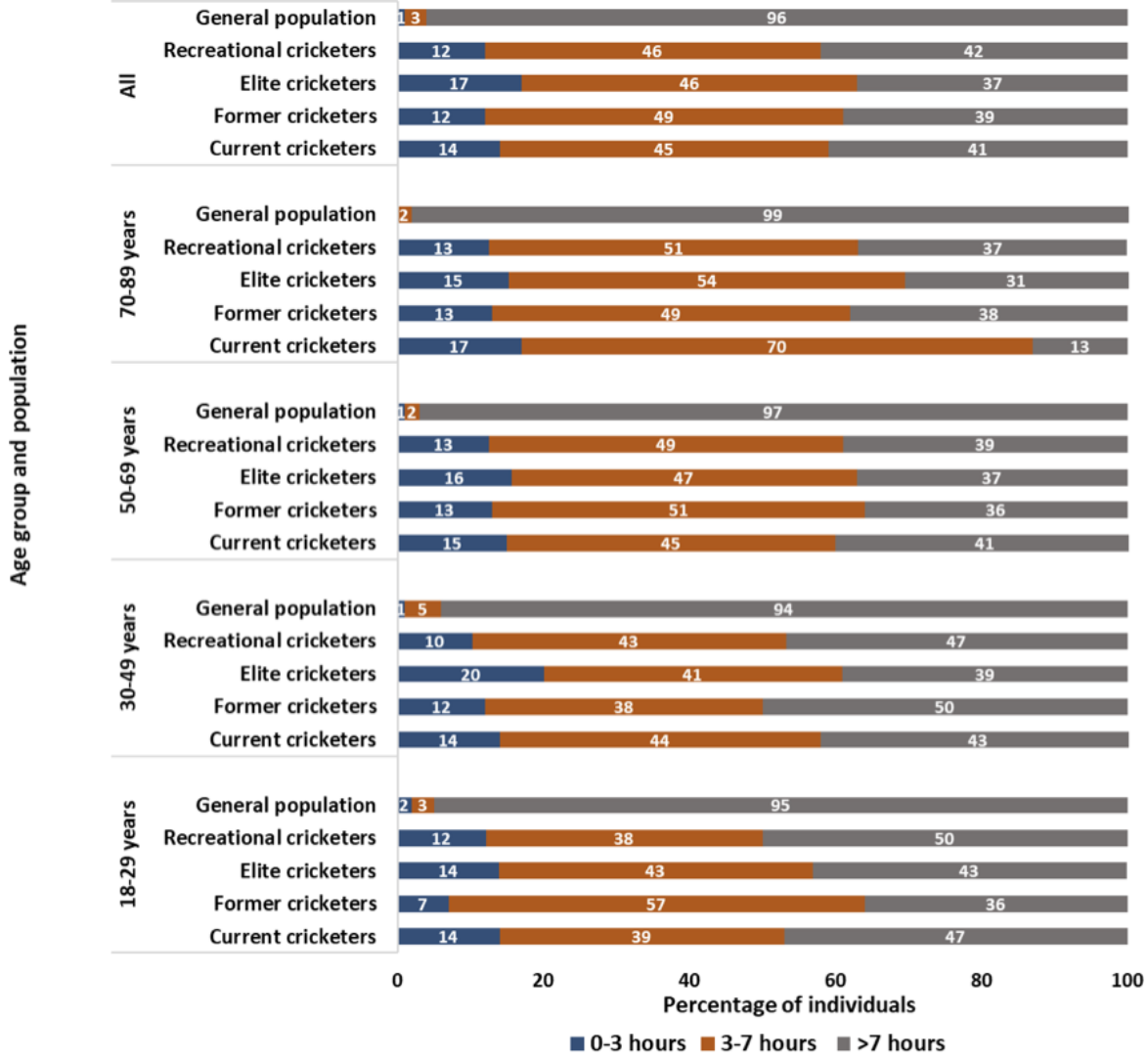

Figure 3 Time spent sitting categorised by age group in current and retired cricketers, elite and recreational cricketers, compared against a non-cricket playing general population sample recreational cricketers=highest level of play: village/social or school/university high-performance cricketers=highest level of play at an elite level: international, county/premier league, academy or county age group.

inaccuracies due to recall bias $^{38}$ and response bias (eg, social desirability). ${ }^{39} 40$ Consequently, self-report data can over- or underestimate true PA, inactivity and sedentary behaviour. ${ }^{41}$ The correlations between selfreport and direct (eg, accelerometer) measures of PA was low-to-moderate. ${ }^{42}$ Though, the health-based PA recommendations were based on studies that used selfreported PA data. ${ }^{22}$ Invited participants were detailed the inclusion and exclusion criteria during recruitment and could self-select for study participation. Due to this recruitment strategy questionnaire response rate nor responder bias can be calculated. Nevertheless, there potentially is non-response bias from this survey, which may have affected the reliability and validity of our data. Also, due to the membership of the email databases used for recruitment, there were few females and ethnic minority groups. As a result, female cricketers and ethnic minority groups were under-represented in our data. Therefore, these findings should not be generalised to all female and minority groups. However, a strength of our study is that it was informed by previous qualitative work in cricketers ${ }^{9}{ }^{43}$ and the overall large sample size. The survey instrument was developed through patient and public involvement, and used validated questions from previous studies. ${ }^{21}$

\section{CONCLUSION}

Current cricketers had a greater odds of meeting the PA guidelines compared with the general population. However, when stratified by playing standard, only elite cricketers had a greater odds of meeting the PA guidelines compared with the general population. Strategies are needed to transition cricketers to an active lifestyle after retirement, since former cricketers had a reduced odds of meeting the PA guidelines compared with the general population.

\section{Author affiliations}

${ }^{1}$ Australian Institute of Sport, Canberra, Australian Capital Territory, Australia

${ }^{2}$ Centre for Sport, Exercise and 0steoarthritis Research Versus Arthritis, University of Oxford, Oxford, UK

${ }^{3}$ Department of Medical and Health Sciences, Linköping University, Linköping, Sweden

${ }^{4}$ Latrobe Sports and Exercise Medicine Research Centre, Latrobe University, Bundoora, Victoria, Australia

${ }^{5}$ Orthopaedic Surgery, Wake Forest School of Medicine, Winston-Salem, North Carolina, USA

${ }^{6}$ Department of Physiotherapy, University of Melbourne, Melbourne, Victoria, Australia

Twitter Garrett Scott Bullock @DrGSBullock and Stephanie R Filbay @stephfilbay

Acknowledgements The authors would like to acknowledge the England and Wales Cricket Board for their assistance in developing the questionnaire and recruiting participants. They would also like to acknowledge the current and former 
cricketers who contributed to developing this study, and the Cricket Health and Wellbeing Study participants for volunteering their time.

Contributors NKP-P, GSB, NKA and SRF conceived the study idea. NKP-P, GSB, NKA and SRF were involved in methodological design and planning. NKP-P, GSB and SRF wrote the first draft of the manuscript. NKP-P, GSB and SRF contributed to statistical analyses. NKP-P, GSB, NKA and SRF all critically revised the manuscript. NKP-P, GSB, NKA and SRF all approved the final version of the manuscript. SRF is the guarantor of this study

Funding The Cricketers Health and wellbeing study is funded by the Centre for Sport, Exercise and Osteoarthritis Research Versus Arthritis-Sports Grant (HFR02510).

\section{Competing interests None declared.}

Patient consent for publication Not applicable.

Ethics approval This cross-sectional study was approved by the NHS Health Research Authority (NRES), London Stanmore Research Ethics Committee (REC 15/ LO/1274).

Provenance and peer review Not commissioned; externally peer reviewed.

Data availability statement Data are available on reasonable request.

Supplemental material This content has been supplied by the author(s). It has not been vetted by BMJ Publishing Group Limited (BMJ) and may not have been peer-reviewed. Any opinions or recommendations discussed are solely those of the author(s) and are not endorsed by BMJ. BMJ disclaims all liability and responsibility arising from any reliance placed on the content. Where the content includes any translated material, BMJ does not warrant the accuracy and reliability of the translations (including but not limited to local regulations, clinical guidelines, terminology, drug names and drug dosages), and is not responsible for any error and/or omissions arising from translation and adaptation or otherwise.

Open access This is an open access article distributed in accordance with the Creative Commons Attribution Non Commercial (CC BY-NC 4.0) license, which permits others to distribute, remix, adapt, build upon this work non-commercially, and license their derivative works on different terms, provided the original work is properly cited, appropriate credit is given, any changes made indicated, and the use is non-commercial. See: http://creativecommons.org/licenses/by-nc/4.0/.

ORCID iDs

Garrett Scott Bullock http://orcid.org/0000-0003-0236-9015

Stephanie R Filbay http://orcid.org/0000-0002-9624-0791

\section{REFERENCES}

1 British Heart Foundation. Physical inactivity report 2017 https:// www.bhf.org.uk/informationsupport/publications/statistics/physicalinactivity-report-2017

2 Lee I-M, Shiroma EJ, Lobelo F, et al. Effect of physical inactivity on major non-communicable diseases worldwide: an analysis of burden of disease and life expectancy. Lancet 2012;380:219-29.

3 Sedentary Behaviour and Obesity Expert Working Group. Sedentary behaviour and obesity: review of the current scientific evidence. London: Department of Health, 2010.

4 Biddle S, Cavill N, Ekelund U. Sedentary behaviour and obesity: review of the current scientific evidence 2010.

5 Heron L, O'Neill C, McAneney H, et al. Direct healthcare costs of sedentary behaviour in the UK. J Epidemiol Community Health 2019;73:625-9.

6 Owen N, Healy GN, Matthews CE, et al. Too much sitting: the population health science of sedentary behavior. Exerc Sport Sci Rev 2010;38:105-13.

7 International Cricket Council. ICC members, 2019. Available: https:// www.icc-cricket.com/about/members/about-our-members

8 Ainsworth BE, Haskell WL, Herrmann SD, et al. 2011 compendium of physical activities: a second update of codes and Met values. Med Sci Sports Exerc 2011;43:1575-81.

9 Filbay SR, Bishop FL, Peirce N, et al. Physical activity in former elite cricketers and strategies for promoting physical activity after retirement from cricket: a qualitative study. BMJ Open 2017;7:e017785.

10 ZIELIŃSKI J, KRÓL-ZIELIŃSKA MA, KUSY K. Changes in physical activity of elite track and field athletes in selected age categories. Studies Phys Culture Tourism 2006;13:185-7.

11 Reifsteck EJ, Gill DL, Brooks D. The relationship between athletic identity and physical activity among former college athletes. Athl Insight 2013;5:271-84.
12 Northern Ireland Assembly. Barriers to sports and physical activity participation, 20102018.

13 Gouttebarge V, Kerkhoffs G, Lambert M. Prevalence and determinants of symptoms of common mental disorders in retired professional rugby union players. Eur J Sport Sci 2016;16:595-602.

14 Rönkkö R, Heliövaara M, Malmivaara A. Musculoskeletal pain, disability and quality of life among retired dancers. J Dance $\mathrm{Med} \mathrm{Sci}$ 2007;11:105-9.

15 Jones ME, Davies MAM, Leyland KM, et al. Osteoarthritis and other long-term health conditions in former elite cricketers. J Sci Med Sport 2018;21:558-63.

16 Cai H, Bullock GS, Sanchez-Santos MT, et al. Joint pain and osteoarthritis in former recreational and elite cricketers. BMC Musculoskelet Disord 2019;20:596.

17 Kanavaki AM, Rushton A, Efstathiou N, et al. Barriers and facilitators of physical activity in knee and hip osteoarthritis: a systematic review of qualitative evidence. BMJ Open 2017;7:e017042.

18 Witkowski S, Spangenburg EE. Reduced physical activity and the retired athlete: a dangerous combination? Br J Sports Med 2008;42:952-3.

19 Harris PA, Taylor R, Thielke R, et al. Research electronic data capture (REDCap)-a metadata-driven methodology and workflow process for providing translational research informatics support. J Biomed Inform 2009;42:377-81.

20 Lyon JA, Garcia-Milian R, Norton HF, et al. The use of research electronic data capture (REDCap) software to create a database of librarian-mediated literature searches. Med Ref Serv $Q$ 2014;33:241-52

21 Committee IR. Guidelines for data processing and analysis of the International physical activity questionnaire (IPAQ)-short and long forms, 2005. Available: https://www.physio-pedia.com/images/c/c7/ Quidelines_for_interpreting_the_IPAQ.pdf

22 Scholes S, Neave A. Health Survey for England 2016: physical activity in adults. Health \& social care information centre, 2017 Available: http://www.hscic.gov.uk/catalogue/PUB13218/HSE201

23 Chau JY, Grunseit AC, Chey T, et al. Daily sitting time and all-cause mortality: a meta-analysis. PLoS One 2013;8:e80000.

24 Bullock GS, Collins GS, Peirce N, et al. Playing sport injured is associated with osteoarthritis, joint pain and worse health-related quality of life: a cross-sectional study. BMC Musculoskelet Disord 2020;21:1-11.

25 NatCen Social Research UCL, Department of Epidemiology and Public Health. Health Survey for England, 2015. [data collection]. UK Data Service, 2017. Available: http://doi.org/10.5255/UKDA-SN8280-1

26 Mansournia MA, Jewell NP, Greenland S. Case-control matching: effects, misconceptions, and recommendations. Eur J Epidemiol 2018;33:5-14.

27 Omorou YA, Erpelding M-L, Escalon H, et al. Contribution of taking part in sport to the association between physical activity and quality of life. Qual Life Res 2013;22:2021-9.

28 Galli N, Gonzalez SP. Psychological resilience in sport: a review of the literature and implications for research and practice. Int J Sport Exerc Psychol 2015;13:243-57.

29 Laborde S, Guillén F, Mosley E. Positive personality-trait-like individual differences in athletes from individual- and team sports and in non-athletes. Psychol Sport Exerc 2016;26:9-13.

30 Eime RM, Young JA, Harvey JT, et al. A systematic review of the psychological and social benefits of participation in sport for adults: informing development of a conceptual model of health through sport. Int J Behav Nutr Phys Act 2013;10:135.

31 Khan KM, Thompson AM, Blair SN, et al. Sport and exercise as contributors to the health of nations. Lancet 2012;380:59-64

32 Verplanken B, Melkevik O. Predicting habit: the case of physical exercise. Psychol Sport Exerc 2008;9:15-26.

33 Malina RM. Tracking of physical activity and physical fitness across the lifespan. Res Q Exerc Sport 1996;67:S-48-S-57.

34 Low J, Williams AM, McRobert AP, et al. The microstructure of practice activities engaged in by elite and recreational youth cricket players. J Sports Sci 2013;31:1242-50.

35 Brannan MGT, Foster CE, Timpson CM, et al. Active 10 - a new approach to increase physical activity in inactive people in England. Prog Cardiovasc Dis 2019;62:135-9.

36 Dunstan DW, Healy GN, Sugiyama T, et al. 'Too Much Sitting' and Metabolic Risk - Has Modern Technology Caught Up with Us? Eur Endocrinology 2010;06:19-23.

37 Hagströmer M, Oja P, Sjöström M. The International physical activity questionnaire (IPAQ): a study of concurrent and construct validity. Public Health Nutr 2006;9:755-62.

38 Coughlin SS. Recall bias in epidemiologic studies. J Clin Epidemiol 1990;43:87-91. 
39 van de Mortel T. Faking it: social desirability response bias in selfreport research. Aus J Advanced Nurs 2008;25:40-8.

40 Adams SA, Matthews CE, Ebbeling CB, et al. The effect of social desirability and social approval on self-reports of physical activity. Am J Epidemiol 2005;161:389-98.

41 Prince SA, Adamo KB, Hamel M, et al. A comparison of direct versus self-report measures for assessing physical activity in adults: a systematic review. Int J Behav Nutr Phys Act 2008;5:56.
42 Prince SA, Adamo KB, Hamel ME, et al. A comparison of direct versus self-report measures for assessing physical activity in adults: a systematic review. Int J Behav Nutr Phys Act 2008;5:56.

43 Filbay SR, Bishop F, Peirce N, et al. Common attributes in retired professional cricketers that may enhance or hinder quality of life after retirement: a qualitative study. BMJ Open 2017;7:e016541.

44 Drinkaware. UK alcohol unit guidance: CMOs' low risk drinking guidelines, 2019. Available: https://www.drinkaware.co.uk/alcoholfacts/alcoholic-drinks-units/latest-uk-alcohol-unit-guidance/ 